Article

\title{
Impacts of Urban Sprawl on Soil Resources in the Changchun-Jilin Economic Zone, China, 2000-2015
}

\author{
Xiaoyan $\mathrm{Li}^{1}{ }^{1} *$, Limin Yang ${ }^{1}$, Yongxing Ren ${ }^{1,2}$, Huiying $\mathrm{Li}^{1,2}$ and Zongming Wang ${ }^{2}$ \\ 1 College of Earth Sciences, Jilin University, Changchun 130012, China; aurora_ylm@sina.com (L.Y.); \\ 15271915264@163.com (Y.R.); lihuiyinghehe@163.com (H.L.) \\ 2 Key Laboratory of Wetland Ecology and Environment, Northeast Institute of Geography and Agroecology, \\ Chinese Academy of Sciences, Changchun 130102, China; zongmingwang@neigae.ac.cn \\ * Correspondence: lxyan@jlu.edu.cn
}

Received: 18 April 2018; Accepted: 4 June 2018; Published: 6 June 2018

check for updates

\begin{abstract}
The Changchun-Jilin Economic Zone (CJEZ) is one of the most rapidly developing areas in Northeast China, as well as one of the famous golden maize belts in the world. This is a case study to assess the impacts of urban sprawl on soil resources using remote sensing imagery and geographic spatial analysis methods. The common urbanization intensity index (CUII), soil quality index, and soil landscape metrics were calculated to reflect urbanization and the response of soil resource. Results showed that the area of soil sealing changed from 112,460 ha in 2000 to 139,233 ha in 2015 , and in the rural region, the area occupied by urbanization nearly kept balance with the area of rural residential expansion. Urban land increased by 26,767 ha at an annual rate of $3.23 \%$ from 2000 to 2015. All seven soil types were occupied during the urbanization process, among which black soil ranked the highest (18,560 ha) and accounted for $69.34 \%$ of the total occupied area. Soils of Grades I (3927 ha) and II (15,016 ha) were $64.75 \%$ of the total occupied soil areas. Urban land expanded in an irregular shape and a disordered way, which led to an increasing large patch index (LPI) and aggregation index (AI), and a decreasing edge density (ED) and Shannon's diversity index (SHDI) of the soil landscape in the study area during 2000-2015. According to the geographically weighted regression (GWR) model analysis, the $R^{2}$ between the CUII and soil landscape metrics decreased from the LPI and ED to SHDI and in turn to AI. The local $R^{2}$ between SHDI, ED, and CUII showed a gradient structure from the inner city to peri-urban areas, in which larger values appeared with strongly intensive urbanization in urban fringes. Soil sealing induced by urbanization has become a significant factor threatening soil, the environment, and food security. How to coordinate regional development and ensure the sustainability of the multiple functions of soil is a problem that needs to be taken into account in the future development of the region.
\end{abstract}

Keywords: urban sprawl; soil resources; soil quality; structure of the soil landscape; the Changchun-Jilin Economic Zone; China

\section{Introduction}

Urbanization is a global process and is regarded as a necessary phase for most of the country's development towards modernization [1]. The latest report from the United Nations showed that the global urbanization process of the rural population is still accelerating and the global urban population is expected to grow to 6.4 billion in 2050 from 3.9 billion in 2014 [2]. Urbanization inevitably leads to the expansion of urban land area. The area of global urban land quadrupled from 1970 to 2000 and the rate of expansion in developing countries even increased after 2000 [3,4]. According to Seto's study, urban land areas in developing countries are projected to increase from $300,000 \mathrm{~km}^{2}$ to $1,200,000 \mathrm{~km}^{2}$ from 2000 to 2050 [5]. The growth of population and unprecedented urbanization not only created positive 
externalities through outstanding economic growth, but also greatly changed natural landscapes and brought enormous environmental and social impacts [6,7]. Much research has been made on the impacts of urban sprawl on landscape, air, water, biodiversity, as well as human health, but not enough attention has been paid on impacts to the structure and functions of soil resources $[1,4,7,8]$.

During the urban expansion process, soils are often polluted with heavy metals, desurfaced, mixed, and compacted [9]. Many studies have been done on soil pollution with heavy metals (HMs) $[4,10]$. Recently, soil sealing and impermeabilization of soils resulting from urbanization have been attracting an increasing amount of interest [7,11,12]. Soil sealing was defined by Duley as a thin layer that limits infiltration through the soil surfaces [9]. Usually, the formation of soil sealing has natural and human factors [10]. Human activity, such as agricultural mechanization, and soil consolidation caused by long-term fertilization, has accelerated the natural soil sealing processes. Further, the spread of urban land leads to a permanent covering of soil surfaces in rural and urban regions. Because of the impermeabilization of soils, soil properties are changed, and exchange of gases, water, and energy are restricted. As a result, the multiple functions of soil, including its production, carrier, resource, habitat, and cultural functions, are obstructed [11]. Moreover, provided soil sealing happens, there is almost no possibility of restoration without a high cost. Soil sealing has been highlighted as one of the principal reasons of soil degradation and is of broad concern [10,11].

Recently, some monitoring schemes have been carried out. The soil sealing in Europe, East China, and the United States with rapid urbanization were studied and some valuable understandings were obtained [11-14]. Research indicated that soil sealing is a typical characteristic of urbanization [11]. Only for China, it has been estimated that there was a total soil sealing area of 25,523 km² since 1990 and the increasing rate quickened after 2000 [12]. The results also indicated that fertile soils distributed in peri-urban areas were seriously jeopardized [13]. During 1990-2006, the area of soil sealing covering on agricultural land was summed up to be $11,890.7 \mathrm{~km}^{2}$ in 27 European Union member states [11]. Human construction activities interrupted the connection between soil and other ecosystem compartments and therefore influenced the soil function. Though there have been considerable publications on threats to soils, seldom have studies qualitatively described the changes in soil resources caused by rapid urbanization [10]. Discord between urbanization and soil resources is a global issue, which is particularly prominent in developing countries.

China entered the stage of rapid urbanization with rapid economic development in the late 1980s. The proportion of the urban population in the whole country increased from $10.6 \%$ to $49.9 \%$ in about 60 years since 1949 [15]. Northeast China is an old industrial region with a high level of urbanization. According to the statistics, the proportion of the urban population in Northeast China was $56.24 \%$ in 2010, which was above the Chinese average of $49.9 \%$ and the world average of $51.8 \%[16,17]$. Rapid urbanization has led to many social and environmental problems including a loss of soil resources. Measuring the geographic traits of soil sealing in response to rapid urbanization can not only offer the basis for studying soil heterogeneity and ecological functions but also explore the interaction between soil landscape and human activities [18].

The Changchun-Jilin Economic Zone (CJEZ) is one of the regions with the most rapid urbanization in Northeast China, which is also one part of the famous black soil region and an important commodity grain base in China [19]. The CJEZ has experienced unprecedented economic development in recent years, especially after the implementation of the policy of Revitalization in Northeast China [20]. Since 2000, the gross domestic product (GDP) of the study area increased by $5.6 \times 10^{3}$ billion RMB, and the non-agricultural population was raised by $496.6 \times 10^{3}$ persons. As a result, the expansion of urban land quickened and led to a substantial increase in the area of soil sealing. Soil sealing has become a serious threat to the environment, food supply, and security. Thus, monitoring the process of soil sealing caused by urbanization and the impact of urbanization on soil resources are especially needed.

Comprehensively using remote sensing and geographic information system (GIS) techniques, the objectives of this paper are (1) to analyze the urban sprawl in the CJEZ over the past 15 years, (2) to 
analyze the characteristics of soil types and soil quality occupied by expended urban land, and (3) to explore the impact of urbanization on the soil landscape.

\section{Materials and Methods}

\subsection{Study Area Descriptions}

The CJEZ is located in the middle part of the province of Jilin $\left(124^{\circ} 50^{\prime} 16.8^{\prime \prime} \mathrm{E}-127^{\circ} 15^{\prime} 44.9^{\prime \prime} \mathrm{E}\right.$, $43^{\circ} 24^{\prime} 7.8^{\prime \prime} \mathrm{N}-44^{\circ} 22^{\prime} 55.2^{\prime \prime} \mathrm{N}$ ) and includes Changchun, Jiutai, Jilin, Yongji, and Shuangyang (Figure 1), covering a total area of $12.9 \times 10^{3} \mathrm{~km}^{2}$. The study area is characterized by the transition of a plain to a mountainous area, in which elevation changes from 19 to $1295 \mathrm{~m}$ from west to east. Accordingly, it has the continental and semi-humid climate of the cold temperate zone, which is characterized by cold winters and cool summers, with a mean annual precipitation and temperature of 570-700 $\mathrm{mm}$ and $4.5-4.8^{\circ} \mathrm{C}$, respectively, with rainfall concentrated mostly between May and September. The CJEZ is also in the famous black soil region.

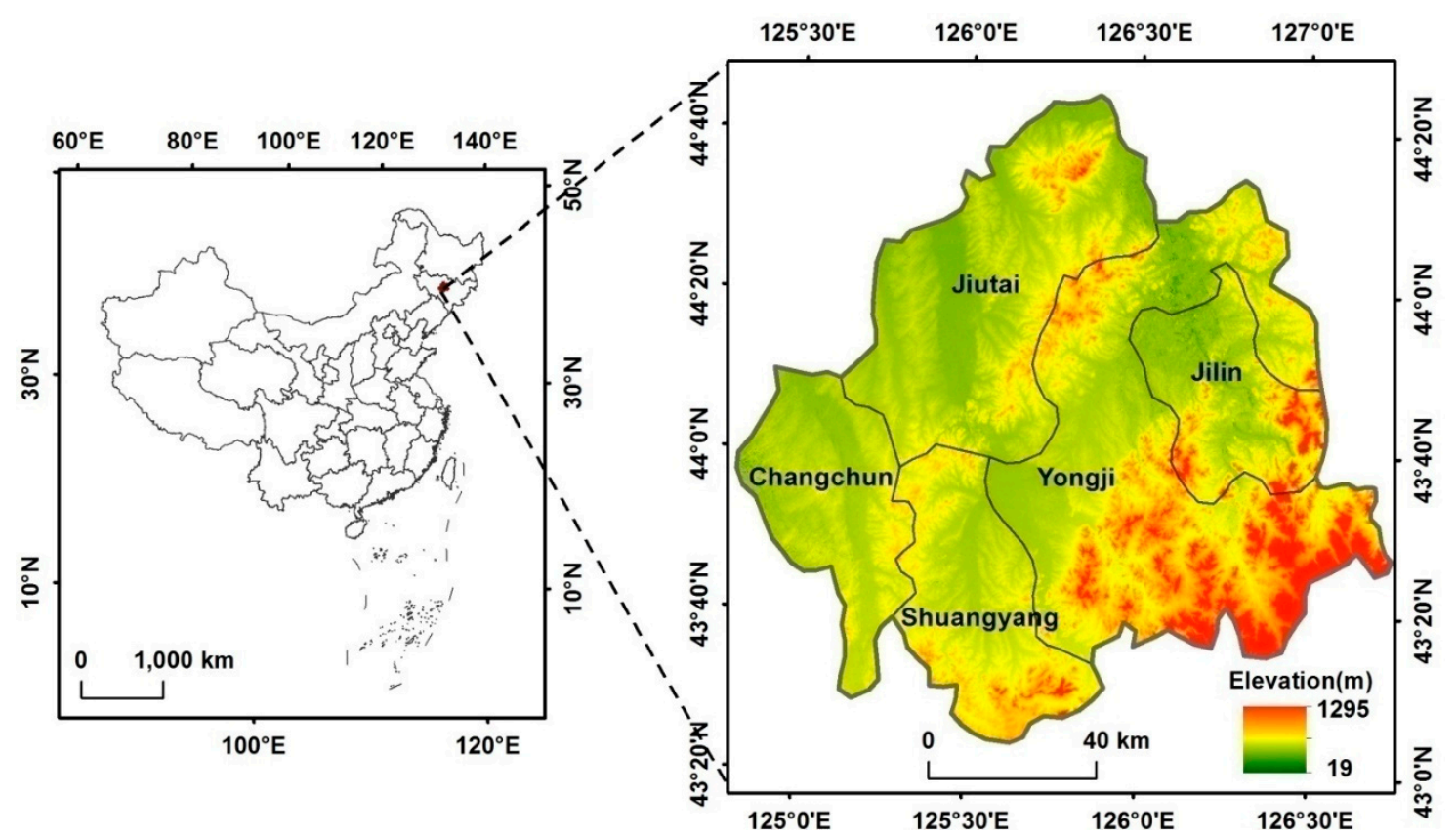

Figure 1. Location of the Changchun-Jilin Economic Zone (CJEZ).

\subsection{Data Sources}

\subsubsection{Land Cover Data}

Land cover maps of the study area were extracted from two sources: the Landsat Thematic Mapper (TM, six scenes) in 2000 and the Landsat Operational Land Imager (OLI, six scenes) in 2015 (Figure 2) with aquisition data between June and October. All images were preprocessed by band synthesis and geo-referenced to 1:100,000 topographic maps with an error within 1.5 pixel. For each image, the ground control points (GCPs) demanded more than 20 points. The land cover classification system includes eight classes (cropland, forestland, waterbody, grassland, urban land, barren land, wetland, and rural settlement). Cropland includes paddy fields and dry farming land. Forestland includes forests, shrubs, and orchards. Waterbody includes streams, rivers, lakes, reservoirs, ponds, and overflow land. Grassland is land covered by natural herbaceous plants with coverage greater than $5 \%$. Urban land is the land used for residence, commerce, industry, recreation, and transportation in cities and towns. Barren land is the land with vegetation cover less than $5 \%$. Wetland includes land with a permanent mixture of water and vegetation that covers extensive areas. Rural settlement 
consists of sparsely populated communities, away from densely populated urban centers. The images were classified into eight types of determined classes using a comprehensive method combined with the object-oriented classification method and the nearest neighbor classifiers [21] (using eCognition 8.64 software [18]) (Figure 2). First, the object-oriented method was used to segment the image into groups of homogeneous pixels so that the variability within the object was minimized [21]. Then, the compactness parameter was used to balance compactness and smoothness. After the objects in the images were segmented, image objects were classified into classes using nearest neighbor (NN) classifiers. To obtain the best interpretation, visual interpretation was carried out to confirm the extraction by inspecting high-resolution images available in Google Earth [21].

The accuracy of land cover has been assessed in previous studies [22,23]. In this study, additional validations including landscape records, GPS locations, and high-resolution Google Earth images of 280 ground truth points for each period were conducted to obtain specific classification accuracies of the land cover. The accuracies of land cover in 2000 and 2015 were $92.4 \%$ and $91.3 \%$, respectively.
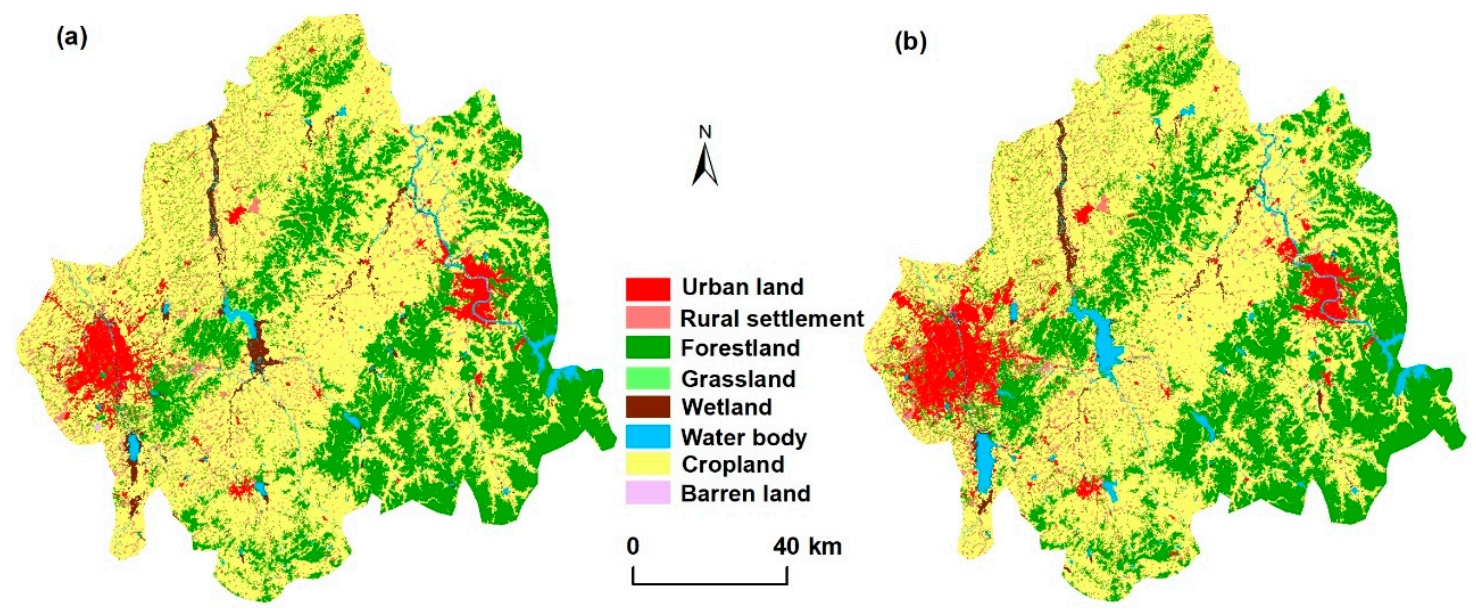

Figure 2. Land cover map of the CJEZ in 2000 (a) and 2015 (b).

\subsubsection{Soil Data}

Soil data included the soil type map and soil survey data. The digital soil type map with a scale of 1:500,000 was offered by the Soil and Fertilizer Station of Jilin province, China. The soil map was digitalized and updated in 2003 . We merged the subcategories of soil classification into seven categories and analyzed the combined categories. In the study area, the main soil types are black soil (Luvic Phaeozem, Food and Agriculture Organization (FAO); 28.0\%), meadow soil (EutricVertisol, FAO; 25.2\%), brown forest soil (Haplic Luvisol, FAO; 24.2\%), white pulp soil (MollicPlanosols, FAO; 13.6\%), and paddy soil (HydragricAnthrosol, FAO; 8.2\%) (Figure 3, Table 1). Approximate correspondence of soil type between Chinese soil classification and FAO reference soil taxonomy was conducted (Table 1).

Table 1. Approximate correspondences of soil groups between Chinese soilclassification and Food and Agriculture Organization (FAO) reference soil taxonomy.

\begin{tabular}{cccc}
\hline No. & Chinese Soil Classification System & FAO Soil Taxonomy & Area (ha) \\
\hline 1 & Black soil & Luvic Phaeozem & $371,645.18$ \\
2 & Brown forest soil & HapicLuvisol & $330,896.95$ \\
3 & Meadow soil & EutricVertisol & $345,896.88$ \\
4 & White pulp soil & EutricPlanosols & $185,757.96$ \\
5 & Paddy soil & HydragricAnthrosol & $111,647.78$ \\
6 & Dark chernozem & Haplic Chernozems & $11,265.07$ \\
7 & Aeolian soil & Arenosol & $10,280.84$ \\
\hline
\end{tabular}




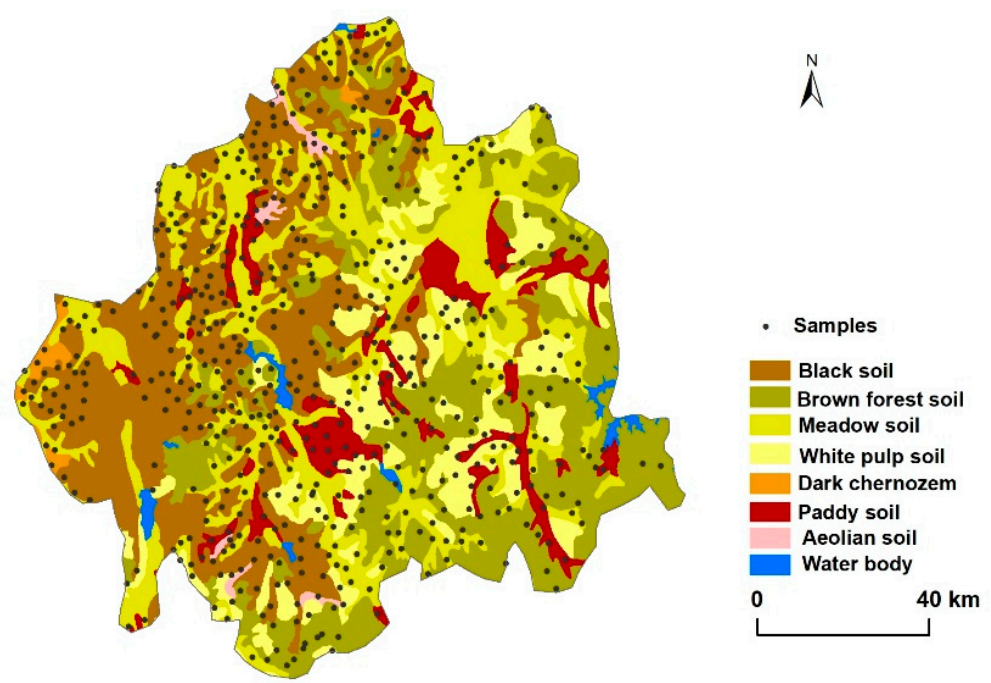

Figure 3. Distributions of soil types and sampling points.

The 619 sample data of the soil survey were obtained from the regional soil fertility investigation from 2006 to 2009 (Figure 3). Each sampling data was a mixture of five subsamples within $200 \mathrm{~m}^{2}$ from the soil surface (the depth was $0-20 \mathrm{~cm}$ ). The data included the soil's physical and chemical properties, as well as agricultural managements used. Samples were air-dried, crumbled, sieved through a $2 \mathrm{~mm}$ sieve and analyzed in the laboratory. The analytical methods for selected indicators are shown in Table 2.

Table 2. Methods used in laboratory analysis for selected indicators.

\begin{tabular}{lcc}
\hline Indicator & Laboratory Analysis Method & Reference \\
\hline Soil organic matter (SOM) & Potassium dichromate oxidation & {$[24]$} \\
Total nitrogen (TN) & Kjeldahl & {$[24]$} \\
Available phosphorus (AP) & Sodium bicarbonate extraction, colorimetric detection & {$[24]$} \\
Available potassium (AK) & Ammonium acetate extraction, flame photometer detection & {$[24]$} \\
Extractable Fe (Afe) & Flame photometer detection & {$[24]$} \\
Cation exchange capacity (CEC) & Ammonium acetate extraction & {$[24]$} \\
pH & Saturated soil paste & {$[24]$} \\
\hline
\end{tabular}

\subsection{Methodology}

\subsubsection{Spatial Analysis of Urbanization}

The common urbanization intensity index (CUII) is an effective method to reflect the dynamics of urban sprawl [25] and has a significant correlation with other widely used indices reflecting the intensity of urbanization, such as population density and the percentage of imperviousness [26]. We used $2 \times 2 \mathrm{~km}$ of blocks as the basic unit to calculate the dynamic of urban sprawl via the following equation:

$$
\mathrm{CUII}_{i}=\frac{A_{i, t+n}-A_{i, t}}{n \times W A_{i}} \times 100
$$

where $\mathrm{CUII}_{i}$ represents the urbanization intensity for spatial unit $i$ during the time span $t$ and $t+n$; $A_{i, t+n}$ and $A_{i, t}$ stands for the urban land area in the year $t+n$ and year $t$, respectively, and $W A_{i}$ is the total area of the spatial unit $i[26]$. 


\subsubsection{Soil Quality Assessment}

Soil quality reflects the soil's ability to perform specific functions [27]. In order to estimate soil quality, seven indicators, i.e., soil organic matter (SOM), total nitrogen (TN), extractable phosphorus (AP), extractable potassium (AK), extractable $\mathrm{Fe}(\mathrm{AFe})$, cation exchange capacity (CEC), and $\mathrm{pH}$, were collected to calculate the soil quality index [28,29]. All indicators were standardized by the standard scoring function (SSF)method [30], in which data were divided into two types according to their function on soil quality-upper limit type and peak limit type. Detailed SSF equations for the indicators are listed in Table 3. A principal component analysis (PCA) method was used to calculate the weights of each indicator. Soil quality index was then calculated via the integrated quality index (IQI). The IQI can be described with the following equation:

$$
\mathrm{IQI}=\sum_{\mathrm{i}=1}^{\mathrm{n}} w_{i} \times s_{i}
$$

where IQI represent the integrated quality index, $w_{i}$ is the weight of the $i$ factor for the soil property derived from the PCA method, and $s_{i}$ is the SSF score of $I$ factor.

Table 3. The standard scoring function (SSF) method and the weights of indicators.

\begin{tabular}{|c|c|c|c|c|c|c|c|c|}
\hline Indicator & FT & $x_{1}$ & $x_{2}$ & & SSF & & PCA & Weight \\
\hline SOM (g/kg) & $\mathrm{U}(\mathrm{x})$ & 13 & 50 & \multirow{6}{*}{$\mathrm{U}(x)=\{$} & \multirow{6}{*}{$\begin{array}{r}0.1 \\
0.9 \times \frac{x-x_{1}}{x_{2-x_{1}}} \\
1\end{array}$} & \multirow{6}{*}{$\begin{array}{c}x \leq x_{1} \\
x_{1}<x<x_{2} \\
x \geq x_{2}\end{array}$} & 0.712 & 0.168 \\
\hline $\mathrm{TN}(\mathrm{g} / \mathrm{kg})$ & $\mathrm{U}(\mathrm{x})$ & 0.3 & 2.5 & & & & 0.647 & 0.153 \\
\hline $\mathrm{AP}(\mathrm{mg} / \mathrm{kg})$ & $\mathrm{U}(\mathrm{x})$ & 1.5 & 4.5 & & & & 0.612 & 0.144 \\
\hline $\mathrm{AK}(\mathrm{mg} / \mathrm{kg})$ & $\mathrm{U}(\mathrm{x})$ & 5 & 250 & & & & 0.682 & 0.161 \\
\hline $\mathrm{AFe}(\mathrm{mg} / \mathrm{kg})$ & $\mathrm{U}(\mathrm{x})$ & 20 & 300 & & & & 0.628 & 0.155 \\
\hline $\mathrm{CEC}(\mathrm{cmol} / \mathrm{kg})$ & $\mathrm{U}(\mathrm{x})$ & 10 & 35 & & & & 0.656 & 0.148 \\
\hline $\mathrm{pH}$ & $\mathrm{R}(\mathrm{x})$ & 5 & 7.05 & $\mathrm{R}(x)=$ & $\left\{\begin{array}{l}0.1 \\
0.9 \times \frac{x-x_{1}}{x_{2-x_{1}}}+0.1 \\
1-0.9 \times \frac{x-x_{1}}{x_{2-x_{1}}}\end{array}\right.$ & $\begin{array}{l}x \leq x_{1} \\
x_{1}<x<x_{2} \\
x \geq x_{2}\end{array}$ & 0.301 & 0.071 \\
\hline
\end{tabular}

FT means function type; PCA means principal component analysis; $x_{1}$ means lower limit; $x_{2}$ means upper limit.

\subsubsection{Metric Analysis of the Soil Landscape}

Metric analysis has been widely used to quantify the spatial structure and pattern of the landscape [31,32]. Guided by previous studies, four landscape metrics with low correlation at the landscape level were selected: the large patch index (LPI), the edge density (ED), Shannon's diversity index (SHDI), and the aggregation index (AI) [10,32]. LPI is the area ratio of the largest patch and statistical unit, which reflects the degree of dominance. ED is calculated via dividing the total length of the patch boundaries by the total area, and increases when the patch shapes become irregular in the statistical unit. SHDI reflects the landscape heterogeneity and is especially sensitive to the non-equilibrium distribution of patch types in the statistical unit. When there is only one patch type in the statistical unit, SHDI is equal to 0; when the number of patch types increases or the area ratio of various patches is similar, SHDI increases accordingly. AI refers to the degree of non-randomness or aggregation of different patch types and the spatial configuration characteristics of landscape components [32]. These metrics characterize the size, composition, shape, and aggregation of the soil landscape.

In our study, the soil map was first masked by the urban land in 2000 and 2015, respectively. The soil map was then intersected with $2 \times 2 \mathrm{~km}$ blocks to add the soil information to each block. Finally, each block was taken as a basically statistic unit to perform the metric analysis using ArcGIS 10.2 software (ESRI, Redlands, CA, USA). Expressions and ecological connotations of these metrics are shown in Table 4. 
Table 4. Descriptions of the landscape metrics used in study.

\begin{tabular}{cccc}
\hline Index & Equation & Ecological Connotation & Unit \\
\hline Largest Patch Index (LPI) & $L P I=\frac{\max A_{i j}}{A} \times 100$ & $\begin{array}{c}\text { To indicate ratio of the largest patch area } \\
\text { to total landscape area. }\end{array}$ & $\%$ \\
\hline Edge Density (ED) & $\mathrm{ED}=\frac{\mathrm{E}}{\mathrm{A}} \times 10^{6}$ & To denote the complexity of patch's shape & $\mathrm{m} / \mathrm{ha}$ \\
\hline $\begin{array}{c}\text { Shannon's Diversity } \\
\text { Index (SHDI) }\end{array}$ & $S H D I=-\sum_{i=1}^{r} p_{i} \ln p_{i}$ & To indicate the landscape heterogeneity. & no \\
\hline Aggregation Index (AI) & $A I=\frac{g_{i j}}{\operatorname{maxg} g_{i j}} \times 100$ & $\begin{array}{c}\text { To indicate the degree of aggregation } \\
\text { among different landscape types. }\end{array}$ & $\%$ \\
\hline
\end{tabular}

After the soil information in each block was acquired, change ratios of the selected metrics between 2000 and 2015 were calculated according to the following formula [10]:

$$
C_{i}=\frac{R_{2 i}-R_{1 i}}{R_{1 i}}
$$

where $C_{i}$ indicates the change ratio of landscape metrics in block $i, R_{1 i}$ is the metrics value of block $i$ in 2000, and $R_{2 i}$ is the metrics value of block $i$ in 2015 .

\subsubsection{Geographically Weighted Regression Model}

Soil types vary in different regions because of environmental heterogeneity. Traditional regression analysis has limitations in reflecting spatial constraints, whereas the geographically weighted regression (GWR) model can overcome such problems by considering locations [10,33,34]. GWR model is a local linear regression method and can generate local parameters to reflect spatial differences, including local $R^{2}$, local model residual, and local coefficient. Therefore the complex spatial differences can be quantitatively simulated and mapped [10].

We selected the GWR model to explore the response of the soil landscape to urban expansion. The CUII of urban land was defined as dependent, and the change ratios of the soil metrics were defined as explanatory variables. The equation for the GWR model was as follows:

$$
y_{j}=\beta_{0}\left(u_{j}, v_{j}\right)+\sum_{i=1}^{k} \beta_{i}\left(u_{j}, v_{j}\right) x_{i j}+\varepsilon_{j}
$$

where $u_{j}$ and $v_{j}$ are the spatial coordinates of the sample point $j, \beta_{0}\left(u_{j}, v_{j}\right)$ is the intercept at the location $j, \beta_{i}\left(u_{j}, v_{j}\right)$ is the estimated local coefficient of the independent variable $x_{i j}$, and $\varepsilon_{j}$ is the error term.

The model was performed in ArcGIS 10.2 software. Before the regressions, CUII and soil metrics data were normalized using the min-max standardized method.

\section{Results}

\subsection{Urban Sprawl in the Past 15 Years}

The overall land use changes of the study area from 2000 to 2015 are listed in Table 5. Results indicated that in 2000, cropland was the dominant land use type, occupying more than $60 \%$ of the total area. In 2000-2015, the area of cropland and wetland decreased dramatically, while that of urban land and the water body increased significantly. The CJEZ had undergone considerable urban expansion since 2000 (Figure 4, Table 5). The area of urban land was 55,193 ha in 2000 and 81,960 ha in 2015, which increased by 26,767 ha in the past 15 years with a 1784 ha yearly increase (3.23\%) (Table 5). Among the area of increased urban land, the proportion of cropland was as high as $92.87 \%$.

The most significant expansion occurred in the peri-urban areas of Changchun and Jilin. In addition, the spatial patterns of urban expansion also reflected the heterogeneity in urbanization 
intensity within the CJEZ (Figure 4, Table 2). Changchun was the most urbanized area in this region and accounted for $62.58 \%$ of the total area with CUII greater than 0.5 (Table 6). Further, the urbanization intensity of Jilin and Shuangyang was higher than the surrounding areas.

Table 5. The conversion matrix of land use types from 2000 to 2015 (ha).

\begin{tabular}{|c|c|c|c|c|c|c|c|c|c|}
\hline $\begin{array}{l}\text { Land Use Type } \\
2000\end{array}$ & \multicolumn{9}{|c|}{2015} \\
\hline Rural settlement & 598 & 54,564 & 45 & & 10 & 50 & & & 55,267 \\
\hline Forestland & 430 & 127 & 351,680 & & 0 & & 2920 & 9 & 355,166 \\
\hline Grassland & 466 & & 233 & 10 & & 120 & 398 & & 1226 \\
\hline Cropland & 24,858 & 540 & 13,644 & 7 & 2191 & 5073 & 729,900 & 6 & 776,219 \\
\hline Barren land & 47 & & 53 & 141 & 0 & 38 & 45 & 184 & 506 \\
\hline Total & 81,960 & 55,258 & 366,504 & 157 & 14,192 & 38,558 & 736,069 & 201 & $1,292,900$ \\
\hline Net change & 26,767 & -36 & 11,338 & -912 & -9165 & 12,622 & $-40,151$ & -306 & \\
\hline Change rate (\%) & 48.50 & -0.07 & 3.19 & -74.35 & -39.24 & 48.66 & -5.17 & -60.39 & \\
\hline
\end{tabular}
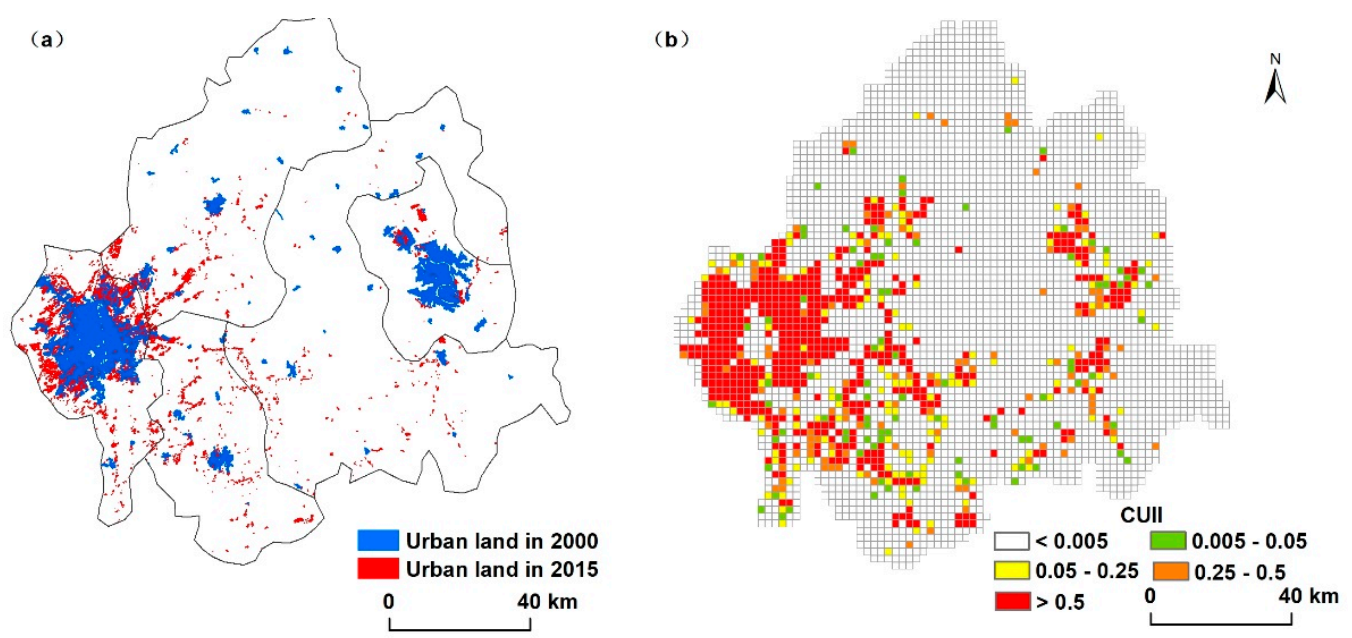

Figure 4. Distribution of urban land (a) and common urbanization intensity index (CUII) (b) in the CJEZ in 2000 and 2015.

Table 6. Average CUII in different regions.

\begin{tabular}{ccccccc}
\hline & CUII & $\mathbf{2 0 . 0 0 5}$ & $\mathbf{0 . 0 0 5 - 0 . 0 5}$ & $\mathbf{0 . 0 5 - 0 . 2 5}$ & $\mathbf{0 . 2 5 - 0 . 5}$ & $>\mathbf{0 . 5}$ \\
\hline \multirow{2}{*}{ Area } & $449,760,000$ & $37,280,000$ & $42,400,000$ & $16,640,000$ & $43,680,000$ \\
\hline \multicolumn{2}{c}{ Proportion (\%) } & 76.26 & 6.32 & 7.19 & 2.82 & 7.41 \\
\hline \multirow{2}{*}{ Changchun } & Area (ha) & $22,465,600$ & $6,180,000$ & $9,751,600$ & $5,021,600$ & $27,333,600$ \\
& Proportion (\%) & 5.00 & 16.58 & 23.00 & 30.18 & 62.58 \\
\hline \multirow{2}{*}{ Jilin } & Area (ha) & $45,554,000$ & $4,583,600$ & $3,842,400$ & $1,766,800$ & $3,756,000$ \\
& Proportion (\%) & 10.13 & 12.30 & 9.06 & 10.62 & 8.60 \\
\hline \multirow{2}{*}{ Jiutai } & Area (ha) & $115,872,000$ & $7,164,400$ & $7,394,800$ & $3,790,000$ & $6,704,400$ \\
& Proportion (\%) & 25.76 & 19.22 & 17.44 & 22.78 & 15.35 \\
\hline \multirow{2}{*}{ Shuangyang } & Area (ha) & $49,490,800$ & $9,504,000$ & $9,706,000$ & $3,032,400$ & $5,118,400$ \\
& Proportion (\%) & 11.00 & 25.49 & 22.89 & 18.22 & 11.72 \\
\hline \multirow{2}{*}{ Yongji } & Area (ha) & $186,924,800$ & $8,736,800$ & $11,117,600$ & $2,982,400$ & 523,200 \\
& Proportion (\%) & 41.56 & 23.44 & 26.22 & 17.92 & 1.20 \\
\hline
\end{tabular}




\subsection{Soil Types Occupied by Expanding Urban Land}

Table 7 showed the soil area in 2000 and 2015. It can be seen from Table 7 that black soil, brown forest soil, and meadow soil were dominant soil types in the study area. Seven soil types were all involved in urban growth during the period of 2000-2015, but the pressure of urban sprawl was not equally distributed over all soil types. Black soil was the largest one occupying (18,560 ha) and accounting for $69.34 \%$ of the total occupied area. Meadow soil was another type of soil that was occupied more area and its contribution was $22.86 \%$. Aeolian soil occupied less area among the seven soil types and its proportion was less than $1 \%$. Though the brown forest soil distributed in large area, the occupied area was only $2.72 \%$ of the total occupied area and accounted for $0.24 \%$ in 2000 . The loss of soil types may therefore represent loss of the whole biological communities unique to that soil type.

Table 7. Soil area in 2000 and 2015.

\begin{tabular}{|c|c|c|c|c|c|c|c|}
\hline \multirow{2}{*}{ Soil Types } & \multicolumn{2}{|c|}{2000} & \multicolumn{2}{|c|}{2015} & \multicolumn{2}{|c|}{ Occupied Soil } & \multirow{2}{*}{$\frac{\text { Occupied Soil/2000 }}{\%}$} \\
\hline & ha & $\%$ & ha & $\%$ & ha & $\%$ & \\
\hline Black soil & $348,791.85$ & 26.35 & $330,231.43$ & 25.51 & $18,560.42$ & 63.65 & 5.32 \\
\hline Brown forest soil & $328,656.07$ & 24.83 & $327,856.13$ & 25.33 & 799.94 & 2.74 & 0.24 \\
\hline Meadow soil & $333,590.70$ & 25.20 & $326,923.64$ & 25.26 & 6667.06 & 22.86 & 2.00 \\
\hline White pulp soil & $181,886.81$ & 13.74 & $180,676.78$ & 13.96 & 1210.03 & 4.15 & 0.67 \\
\hline Paddy soil & $109,682.42$ & 8.29 & $108,411.35$ & 8.37 & 1271.07 & 4.36 & 1.16 \\
\hline Dark chernozem & $10,834.17$ & 0.82 & $10,232.84$ & 0.79 & 601.32 & 2.06 & 5.55 \\
\hline Aeolian soil & $10,189.33$ & 0.77 & $10,139.89$ & 0.78 & 49.44 & 0.17 & 0.49 \\
\hline
\end{tabular}

\subsection{Quality Evaluation of the Sealed Soils}

According to the results of the IQI values for the soil quality assessment, the soil quality of the CJEZ was moderate, and Grade III was the dominant grade, covering an area of 1,020,913 ha (38.23\% of the total area of soils) (Figure 5, Table 7). The soil area of Grades II and IV were 687,110 ha and 583,058 ha, accounting for $25.77 \%$ and $21.86 \%$ of the total area of soils, respectively. Only a small portion of soils were Grade I and Grade V, accounting for 9.15\% (244,037 ha) and 4.94\% (131,680 ha), respectively. Spatially, the highest values of IQI were distributed in the western and eastern areas, and the lower values (including Grades IV and V mainly) appeared in the middle part of the region. A downward trend was manifested from the west and east to the middle part of the study region.

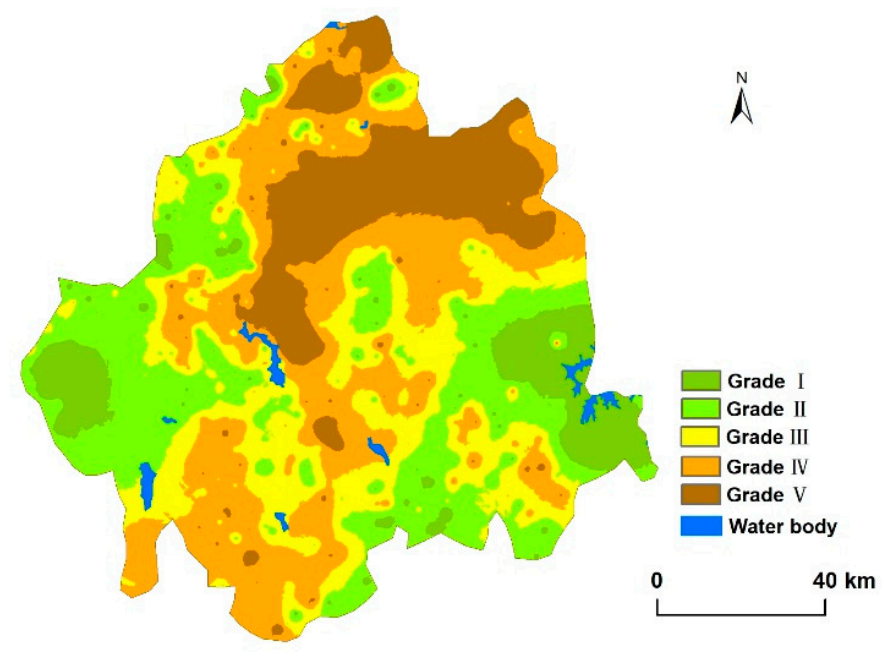

Figure 5. Distribution map of soil quality of the CJEZ.

Based on our analyses (Table 8), the total area of soils occupied by urban expansion in the past 15 years were up to 29,253 ha. An amount of $64.75 \%$ of the soil area occupied by urbanization were 
Grades I (3927 ha) and II (15016 ha) soils, which accounted for $13.42 \%$ and $51.33 \%$, respectively. Grades IV (465 ha) and V (5725 ha) soils were $21.16 \%$ of the expanding urban area. The soil quality analysis of sealed soils indicated that the soils with high quality have a higher risk of being sealed.

Table 8. Quality of soils urbanized in the CJEZ.

\begin{tabular}{ccccc}
\hline & \multicolumn{2}{c}{ Area of Soil } & \multicolumn{2}{c}{ Occupied by Expanded Urban Land } \\
\hline & Area (ha) & Proportion (\%) & Area (ha) & Proportion (\%) \\
\hline Grade I & 244,037 & 9.15 & $3,927.24$ & 13.42 \\
Grade II & 687,110 & 25.77 & $15,016.32$ & 51.33 \\
Grade III & $1,020,913$ & 38.28 & $4,119.93$ & 14.08 \\
Grade IV & 583,058 & 21.86 & 464.67 & 1.59 \\
Grade V & 131,680 & 4.94 & 5725.17 & 19.57 \\
\hline
\end{tabular}

\subsection{Relationships between Soil Landscape and Urban Expansion}

The change rates of soil landscape metrics were calculated on the condition of CUII $>0$ using $2 \mathrm{~km}$ blocks, and the Jenks break point method was used to map the changes (Figure 6).
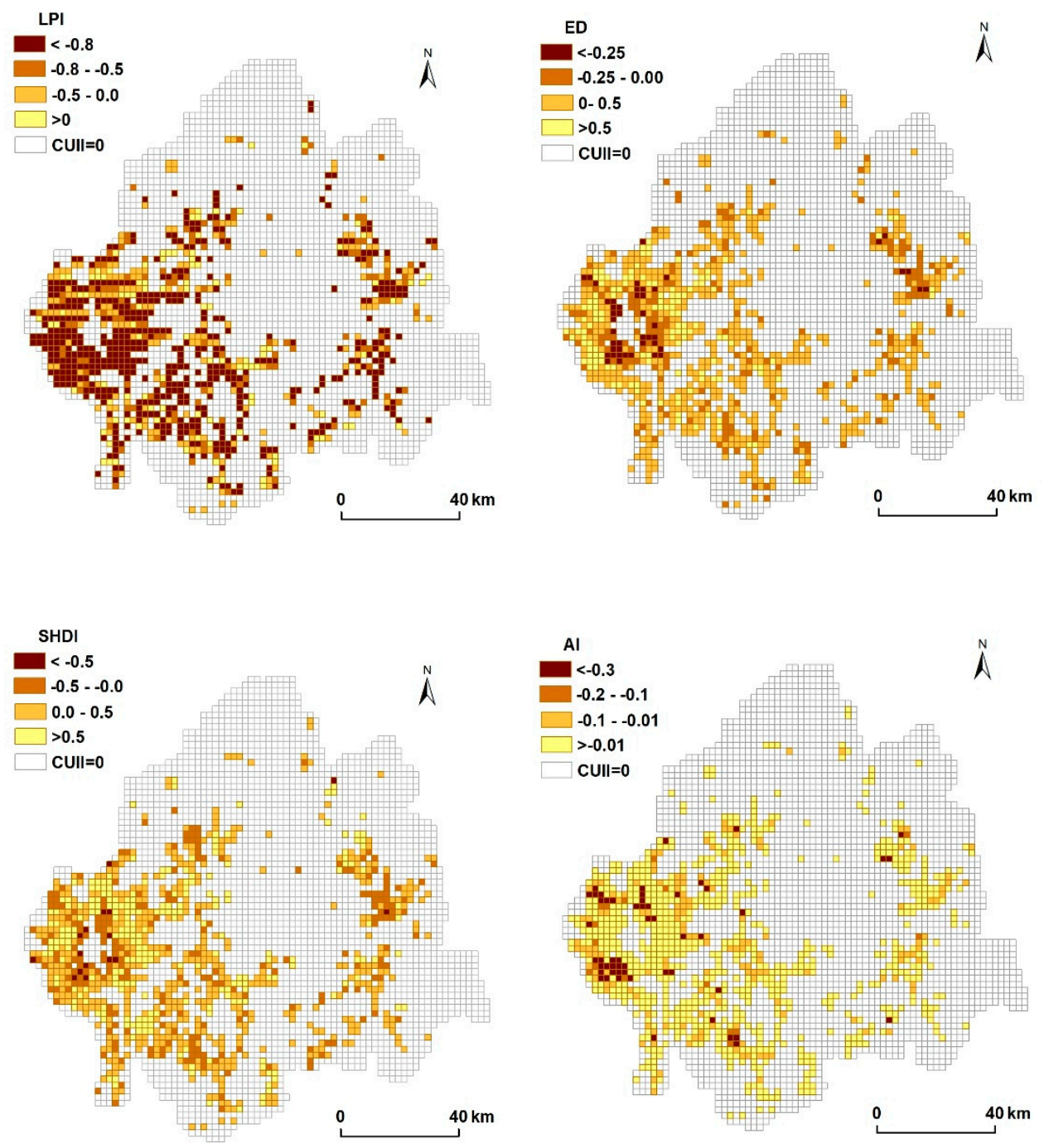

Figure 6. Change rates of soil landscape metrics during 2000-2015. 
It can be seen in Figure 6 and Table 9 that the mean change rate of the large patch index dramatically reduced from 2000 to 2015 when the soils become sealed and fragmented, resulting in more even patch areas in each block. The average change rate of SHDI and ED of the study area exhibited an increasing trend in 2000 and 2015, signifying increased instability, fragmentation, and irregularity of the soil landscapes. Moreover, the change rates of SHDI and ED represented a significant spatial structure. The inner city and suburban areas experienced an obvious circular structure with a decreased value in the inner city and increased value in the peri-urban area. AI was the only metric that decreased in the whole study area during the study span. Declines of AI denoted that soil landscapes became less dominant and aggregated. An obvious decrease in AI occurred in the west and north of Changchun, while the AI in the remaining areas did not obviously change. Among the four metrics, the change rate of SHDI was the largest and that of AI was the smallest.

Table 9. Change ratio and the parameters of the soil landscape metrics in GWR.

\begin{tabular}{ccccc}
\hline & Ratio & AIC $_{\mathbf{c}}$ & $\mathbf{R}^{2}$ CUII & Adjusted $\mathbf{R}^{2}$ CUII \\
\hline LPI & -0.6386 & -1346.71 & 0.6024 & 0.4925 \\
ED & 0.2170 & -1429.56 & 0.5776 & 0.5049 \\
SHDI & 1.1619 & -1326.56 & 0.5059 & 0.4390 \\
AI & -0.0469 & -1245.93 & 0.3500 & 0.3456 \\
\hline
\end{tabular}

The GWR model was introduced to reflect the impact of intensity of urban sprawl on the soil landscape metrics (Figure 7). Some local varying parameters including the coefficient, adjusted $R^{2}$, and standard residual (Stdresid) of each grid were produced by GWR, all exhibiting obvious spatial variability. A strong negative relationship between LPI and CUII (Figure 7a) and positive relationships between ED, SHDI, and CUII (Figure $7 b, c$ ) in blocks were reflected with intensive urbanization. For the LPI of soil, the obvious positive driving effect of CUII was mainly shown in the inner city of Changchun and Jilin. As for ED and SHDI, due to the inhomogeneity of urban sprawl in the direction, the CUII was anisotropic and thus led to the spatial anisotropic characteristics of ED and SHDI, especially for the local varying characteristic of Changchun. For AI, negative effects spread throughout the research area, and the correlation coefficient decreased from northeast to southwest (Figure 7d).

(a) GWR analysis betwwen LPI and CUII

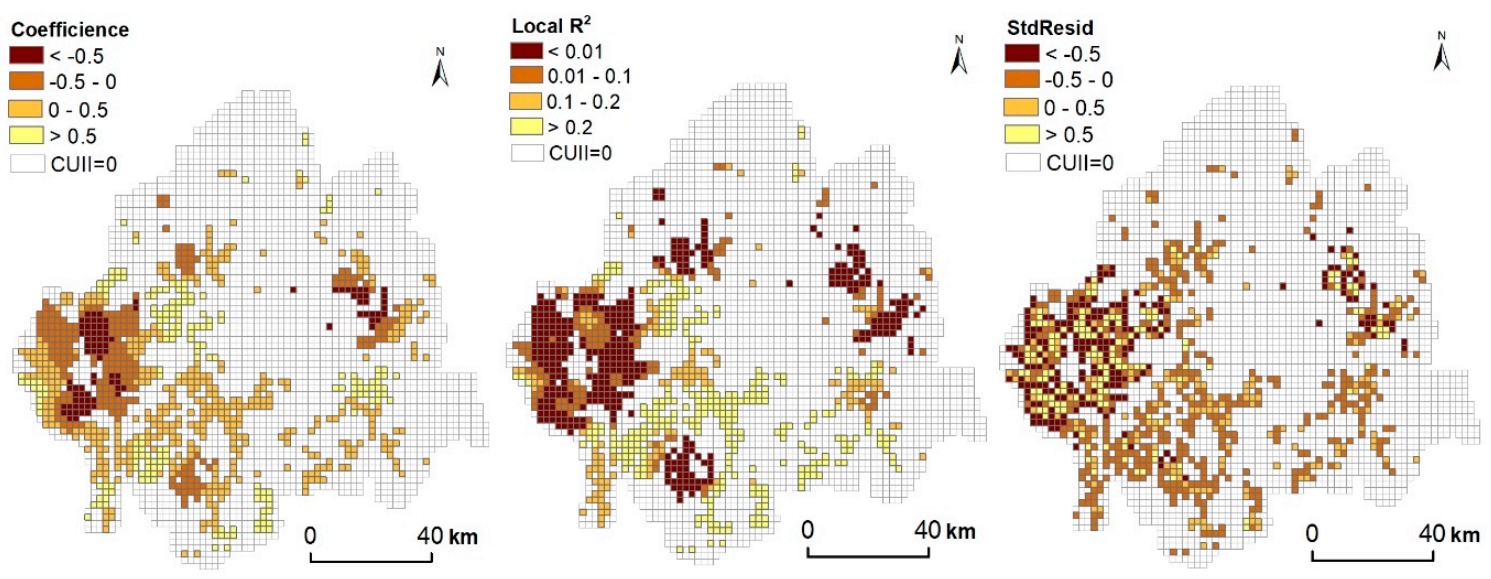

Figure 7. Cont. 
(b) GWR analysis betwwen ED and CUII
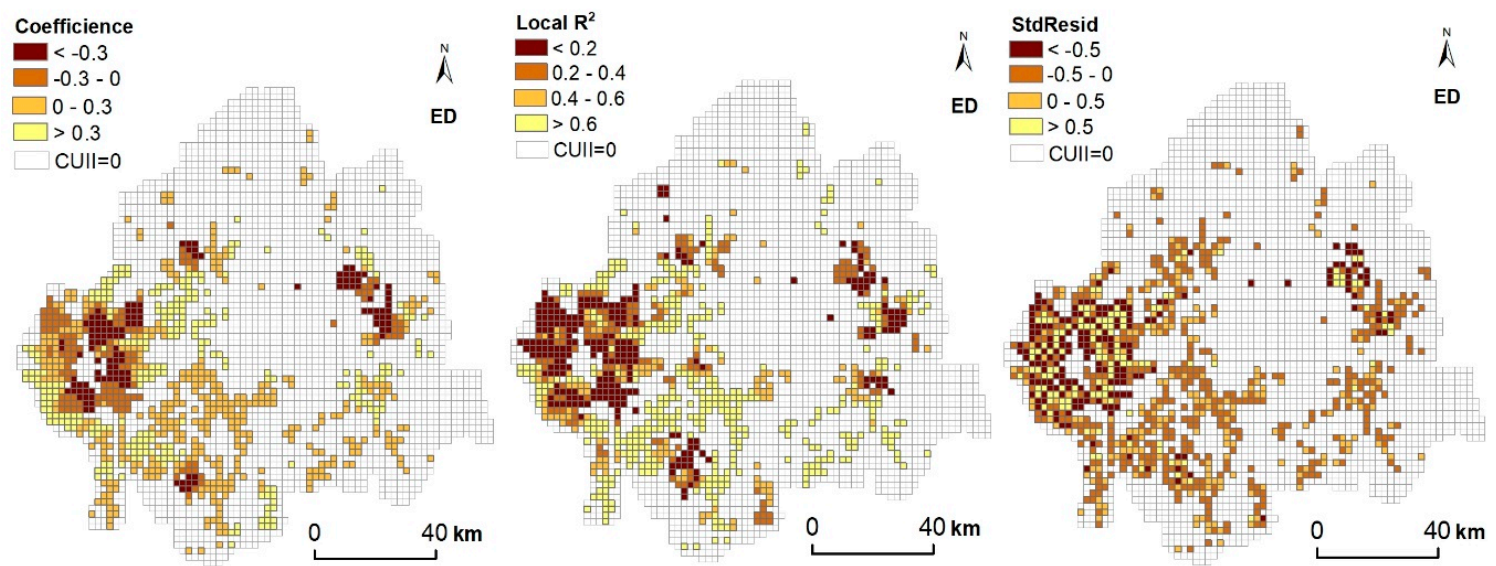

(c) GWR analysis betwwen SHDI and CUII
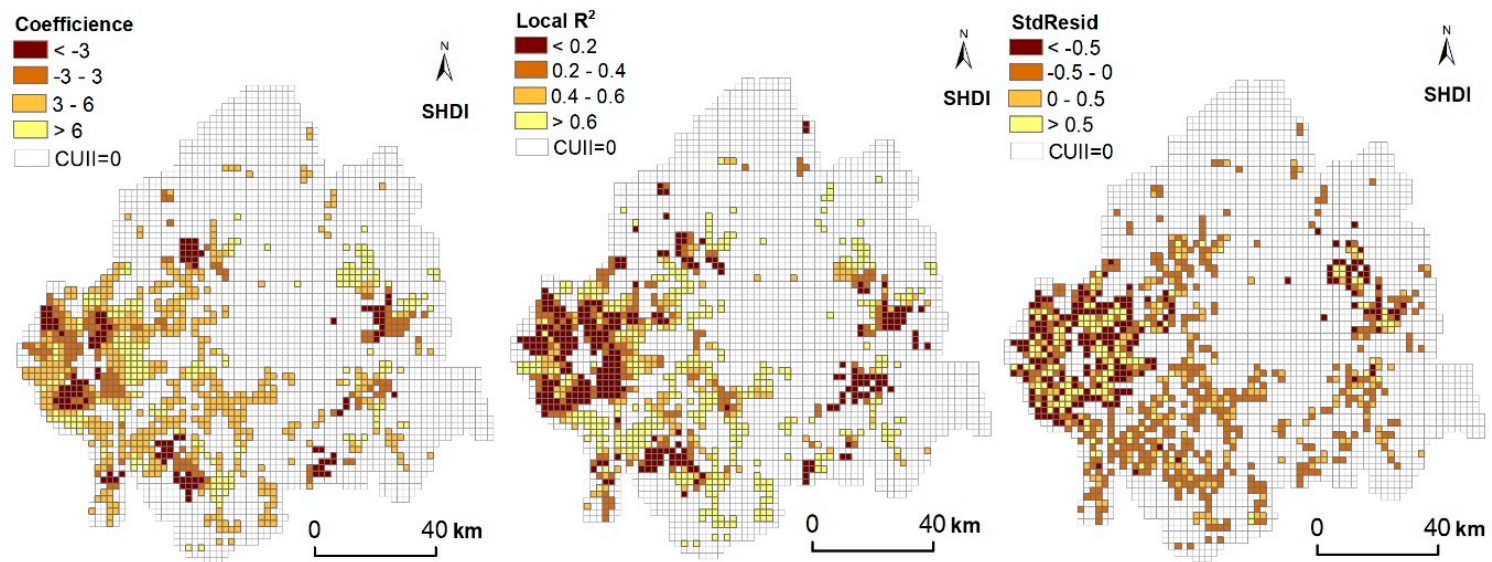

(d) GWR analysis betwwen $\mathrm{Al}$ and CUII
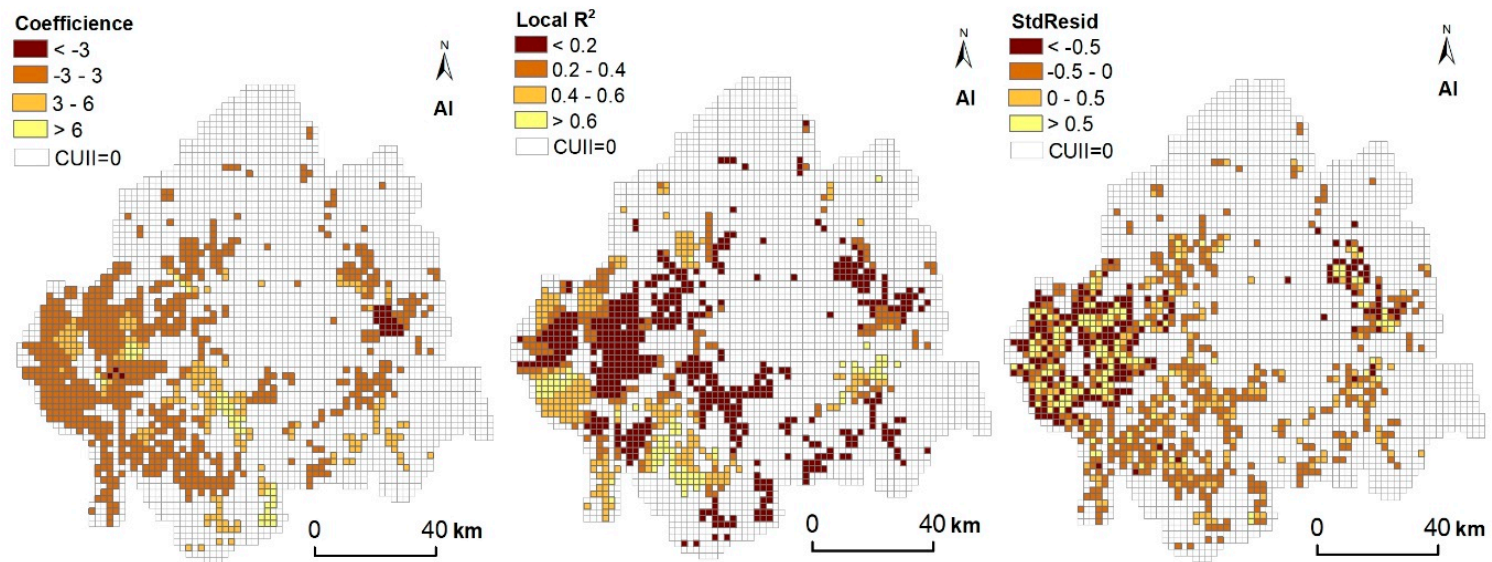

Figure 7. Local varying estimates of relationships between changes of (a) LPI and CUII, (b) ED and CUII, (c) SHDI and CUII, and (d) AI and CUII.

\section{Discussion}

\subsection{Charicteristics of Soil Sealing in the Expanding Urban Land}

Generally, urban sprawl appeared with the increasing population and intensification of economic activities. Urbanization means a conversion of natural or agricultural systems to impermeabilization, 
and this change was a leading cause of loss [34]. The conflicts between development and food security were always there. For urbanization in Northeast China, policy was one of the determinants in accelerating rapid urbanization [35]. The aim of establishing the CJEZ was, on the one hand, to make full use of the radiation driving effect of the central cities and to quicken regional development. On the other hand, the aim was to take the role of the satellite city around the large cities to alleviate the pressures on population and environment of big cities [31]. The study area witnessed unprecedented rapid urban land development since the implementation of the policy of revitalizing Northeast China. From2000 to 2015, the annual expanding rate of urban land in the CJEZ (3.23\%) was higher than the mean value of the Northeast China (2.09\%, during 2000 to 2010$)$ and the whole country (2.75\%, during 2000 to $2010 ; 2.15 \%$, during 2006 to 2014), but lower than that of the middle region of China (5.44\%, during 2000 to 2010; 4.68\%, during 2006 to 2014) [16,36].

It can be seen from Figure 4 and Table 6 that, in the CJEZ, the areas with the largest expanding area of urban land (accounting for $35 \%$ of the total) and the highest expanding intensity of urban land (contributing $62.58 \%$ for the area of CUII $>0.5$ ) were still found in Changchun (Figure 4). Changchun is located in the middle part of the Songneng Plain and the geomorphology consists of platforms $(70 \%)$ and plains $(30 \%)$. This means that human construction activities encountered fewer obstacles when the urban area was sprawling. At the same time, soils in Changchun consists mainly of black soil and meadow soil, which accounted for $49.78 \%$ and $29.06 \%$ of the farmland, respectively, and these two soil types were generally located in flat areas in close proximity to built-up areas in 2000 . Therefore, these two soils lost a great amount of area due to urban sprawl. The results showed the largest area of occupied soils in this region were black soil (63.65\% of the total occupied area) and meadow soil ( $22.86 \%$ of the total occupied area) (Figure 4 ). Once sealed, these areas would not likely be available for food production again.

We also found that soils with the highest quality were distributed around Changchun (Grades I and II accounting for more than 55\% of the total area) (Table 8). Despite the implementation of some farmland protection policies in this area, the rapid expansion of urban land is still consuming a large amount of high-quality cropland (Figure 5). A similar conclusion was drawn in the study conducted in the United States [37]. Consequently, the excessive loss of high quality soil continuously would definitely result in dramatically decreased food production and lead to a food security crisis. Coordinating the contradiction between rapid urbanization and cropland protection has become a problem that must be solved in regional sustainable development.

\subsection{Impact of Urban Expansion on Soil Landscape}

Landscape metrics have proven to be an effective way to investigate the evolution or dynamics of natural resources in response to urbanization $[10,18,25]$. Soils are dynamic components of terrestrial ecosystems, but the dynamics of the soil landscape were not given as the same concerns as the fate of others [10]. In our study, LPI, ED, SHDI, and AI were used to represent landscape characteristics of soil with urbanization. In sum, the dynamics of the soil landscape patterns were largely explained by the spatial characteristics of the spreading urban land. Urban land expanded in a disorderly way of strongly fragmented and irregularly shaped areas via interspersing among soil patches. As a result, strong relationships between the soil landscape pattern and the intensity indicator of urbanization were found in the rapid urbanization blocks, such as peri-urban areas (Figure 7). These indicated that the soil area decreased sharply, and even some soil types disappeared completely because of the expansion of urban land. All of this could lead to the abandonment of soils and result in a failure of their function in the ecological environment.

Previous studies reflected the impact of urbanization on soil landscape via comparison or correlation analysis methods [10,38]. However, the kind of relationships in space between urbanization intensity and the soil landscape has not been clearly presented. We used GWR to describe the local varying parameter spatially and provide a quantitative contribution of urbanization to the change indifferent metrics of the soil landscape. Previous studies showed that the LPI and AI of the soil 
landscape will decline [10,39], while SHDI and ED will ascend with rapid urbanization [39], which is consistent with the statistic of the mean change ratio in our study. Nevertheless, in space, the SHDI and ED showed the gradient structure from the inner city to peri-urban areas, in which the increasing value appeared with strongly intensive urbanization (Figure 6 and Table 9).

According to Dietzel's theory of urbanization, urbanization exhibits alternating cyclic patterns of diffusion and coalescence [40]. This theory implies that the threshold of the dynamics of landscape patterns exist as urbanization intensifies, which has been proven in previous studies of landscape fragmentation and landscape diversity $[16,18]$. Rui [10] compared 28 cities/counties with gradients in urbanization intensity to test whether or not the certain threshold also existed in soil landscape patterns, and the results showed that there was no threshold for soil landscape patterns. In our study, the expanding pattern of urban areas was a centralized model around the central city (Figure 4). Though all types of soil were occupied by urban sprawl, no soil type disappeared (Figure 4). Following the general model of urban development and Rui's study result, some distinct soil types with unique physical structures and history of formation may be in danger of elimination, which would result in a substantial loss of below and above ground biodiversity.

\subsection{Implications and Limitations}

It is worth noting that various irreversible impacts on the structure and functions of soil resources brought by unprecedented rapid urbanization affected the soil's capacity to deliver their diverse services and functions for human living and development. The dynamics trend reflected not only the tendencies of general urbanization in the CJEZ, but also mirrored the process of global urbanization [10]. In addition, the rapid urban sprawl in the CJEZ consumed a large number of good quality soils (Figure 5) that will never come back to agricultural use again. The researchers obtained essentially the same results in the United States, Europe, etc., in which high-quality soil resources were found to be in danger of great loss [11,41]. All of these highlighted the significance of soil sealing as a critical global issue. However, soil resources of developing countries experiencing fast urbanization have not received enough attention. Introducing the frameworks and quantitative analysis methods to conduct the changes of soil sealing under rapid urbanization should be pushed forward in the future.

There are still limitations associated with our study. We only chose $2 \times 2 \mathrm{~km}$ as a basic unit to conduct the spatial analysis according to the comparative results of the existing research and did not quantitatively analyze the effects of different scales, though the scale effect was very prominent in the window analysis. Furthermore, limited by the sampling data, we simply analyzed the urbanization since 2000. Analysis of longer time sequences would give a better understanding of the dynamics of urbanization intensity and their impacts on the pattern, process, and functions of soil.

\section{Conclusions}

Soil sealing induced by urbanization has been considered as a serious threat to soil degradation, the environment, and food security. This study contributes to the quantitative analysis of urbanization and its influences on quantity, quality, and landscape of soil resources. The results are fundamental for governments for formulating policies against soil degradation within urban planning and regional development strategies.

Our study demonstrated the effectiveness of combining data of urban sprawl and change in soil resource in a quantitative way to describe the response of soil to rapid urban expansion. Results showed that the Changchun-Jilin Economic Zone witnessed a rapid urbanization process from 2000 to 2015. Sprawling urban land occupied a large number of high quality cropland in the suburbs, which was a significant factor for the change in soil landscape and jeopardized food production. How to coordinate regional development and ensure the sustainability of the multiple functions of soil, so as to guarantee agricultural production, needs to be determined for the sake of future development in the region. 
Author Contributions: X.L. conceived and wrote the paper; Z.W. revised the paper; L.Y. and H.L. analyzed the data; Y.R. summed up the literature concerned.

Acknowledgments: This work is supported by the Strategic Priority Research Program of the Chinese Academy of Sciences (XDA19040500), the Natural Science Foundation of China (No. 41671219), the Key Project for Field Station Alliance, Chinese Academy of Sciences (KFJ-SW-YW026), and the Regional Project: comparative study of land use and geological environment of black soil zones in China and the US (No. DD20160104).

Conflicts of Interest: The authors declare no conflict of interest.

\section{References}

1. Shahbaz, M.; Sbia, R.; Hamdi, H.; Qzturk, I. Economic growth, electricity consumption, urbanization and environmental degradation relationship in United Arab Emirates. Ecol. Indic. 2014, 45, 622-631. [CrossRef]

2. United Nations. World Urbanization Prospects the 2011 Revision; United Nations: New York, NY, USA, 2012.

3. Seto, K.C.; Guneralp, B.; Reilly, M.K. A meta-analysis of global urban land expansion. PLoS ONE 2011, 6, e23777. [CrossRef] [PubMed]

4. Deng, X.Z.; Huang, J.K.; Rozelle, S.; Zhang, J.P.; Li, Z.H. Impact of urbanization on cultivated land changes in China. Land Use Policy 2015, 45, 1-7. [CrossRef]

5. Seto, K.C.; Fragkias, M.; Guneralp, B.; Reilly, M.K. Global forecasts of urban expansion to 2030 and direct impacts on biodiversity and carbon pools. Proc. Natl. Acad. Sci. USA 2012, 109, 16083-16088. [CrossRef] [PubMed]

6. Lee, D.; Choe, H. Estimating the impacts of urban expansion on landscape ecology: Forestland perspective in the greater Seoul metropolitan area. J. Urban Plan. Dev. (ASCE) 2011, 137, 425-437. [CrossRef]

7. Liu, Q.S.; Liang, F.Y.; Bi, X.L.; Duffy, R.; Zhao, Z.P. Effects of urbanization and industrialization on agricultural land use in Shandong Peninsula of China. Ecol. Indic. 2011, 11, 1710-1714. [CrossRef]

8. Deshpande, A.; Mishra, P.K. Urbanization, air pollution and human health. J. Environ. Res. Dev. 2007, 3, 305-317.

9. Duley, F.L. Surface factors affecting the rate of intake of water by soils. Soil Sci. Soc. Am. J. 1939, 4, 60-64. [CrossRef]

10. Xiao, R.; Su, S.L.; Zhang, Z.H.; Qi, J.G.; Jiang, D.W.; Wu, J.P. Dynamics of soil sealing and soil landscape patterns under rapid urbanization. Catena 2013, 109, 1-12. [CrossRef]

11. Scalenghe, R.; Marsan, F.A. The anthropogenic sealing of soils in urban areas. Landsc. Urban Plan. 2009, 90, 1-10. [CrossRef]

12. Li, J.D.; Deng, J.S.; Gu, Q.; Wang, K.; Ye, F.J.; Xu, Z.H.; Jin, S.Q. The accelerated urbanization process: A threat to soil resources in Eastern Chin. Sustainability 2015, 7, 7137-7155. [CrossRef]

13. Xiao, R.; Su, S.L.; Wang, J.Q.; Zhang, Z.H.; Jiang, D.W.; Wu, J.P. Local spatial modeling of paddy soil landscape patterns in response to urbanization across the urban agglomeration around Hangzhou Bay, China. Appl. Geogr. 2013, 39, 158-171. [CrossRef]

14. Biasioli, M.; Barberis, R.; Ajmone-marsan, F. The influence of a large city on some soil properties and metals content. Sci. Total Environ. 2006, 356, 154-164. [CrossRef] [PubMed]

15. Zhang, X.L.; Chen, J.; Tan, M.Z.; Sun, Y.Z. Assessing the impact of urban sprawl on soil resources of Nanjing city using satellite images and digital soil databases. Catena 2007, 69, 16-30. [CrossRef]

16. Kuang, W.H.; Liu, J.Y.; Dong, J.W. The repid and massive urban and industrial land expansions in China between 1990 and 2010: A CLUD-based analysis of their trajectories, patterns, and drivers. Landsc. Urban Plan. 2016, 145, 21-33. [CrossRef]

17. Li, W.B.; Wang, D.Y.; Li, H.; Liu, S.H. Urbanization-induced site condition changes of peri-urban cultivated land in the black soil region of northeast China. Ecol. Indic. 2017, 80, 215-223. [CrossRef]

18. Uuemaa, E.; Roosaare, J.; Danal, A.; Mander, U. Spatial correlograms of soil cover as an indicator of landscape heterogeneity. Ecol. Indic. 2008, 8, 783-794. [CrossRef]

19. Lee, N.J. Northeast Asian economic cooperation and the Korean Peninsula Economy: The impact of the Changjitu development Plan. KoreaJ 2011, 51, 130-163.

20. Tan, J.T.; Zhang, P.Y.; Lo, K.; Li, J.; Liu, S.W. Conceptualizing and measuring economic resilience of resource-based cities: Case study of Northeast China. Chin. Geogr. Sci. 2017, 27, 471-481. [CrossRef] 
21. Man, W.D.; Wang, Z.M.; Liu, M.Y.; Lu, C.Y.; Jia, M.M.; Mao, D.H.; Ren, C.Y. Spatio-temporal dynamics analysis of cropland in Northeast China during 1990-2013 based on remote sensing. Trans. CSAE 2016, 32, $1-10$.

22. Definiens AG. Definiens Professional 8.6 User Guide; Definiens AG: Munchen, Germany, 2011.

23. Li, X.Y.; Li, H.Y.; Zhang, Y.N.; Yang, L.M. Spatial patterns and the regional differences of rural settlements in Jilin Province, China. Sustainability 2017, 9, 2170. [CrossRef]

24. Lu, R.K. Analytical method of soil and agricultural chemistry. Chin. Soil Ecol. 2000, 64, 194-200.

25. Su, S.; Xiao, R.; Jiang, Z.; Zhang, Y. Characterizing landscape pattern and ecosystem service value changes for urbanization impacts at an eco-regional scale. Appl. Geogr. 2012, 34, 295-305. [CrossRef]

26. Tate, C.M.; Cuffney, T.F.; Mcmahon, G.; Giddings, E.M.P.; Coles, J.F.; Zappia, H. Use of an urban intensity index to assess urban effects on streams in three contrasting environmental settings. Am. Fish. Soc. Symp. 2005, 47, 291-315.

27. Qi, Y.; Darilek, J.L.; Huang, B.; Zhao, Y.; Sun, W.; Gu, Z. Evaluating soil quality indices in an agricultural region of Jiangsu Province, China. Geoderma 2009, 149, 325-334. [CrossRef]

28. Andrews, S.S.; Karlen, D.L.; Mitchesll, J.P. A comparison of soil quality indexing methods for vegetable production systems in Northern California. Agric. Ecosyst. Environ. 2002, 40, 25-45. [CrossRef]

29. Li, X.Y.; Li, H.Y.; Yang, L.M.; Ren, Y.X. Assessment of soil quality of croplands in the Corn Belt of Northeast China. Sustainability 2018, 10, 248. [CrossRef]

30. Fazel, R.; Rossana, M.; Hossein, A.B.; Zahra, F.; Sima, R.B. Assessment of soil quality indices in agricultural lands of Qazvin province, Iran. Ecol. Indic. 2014, 40, 19-26.

31. Geri, F.; Amici, V.; Rocchini, D. Human activity impact on thy heterogeneity of Mediterranean landscape. Appl. Geogr. 2010, 31, 292-302.

32. Li, H.L.; Jian, P.; Liu, Y.X.; Hu, Y.N. Urbanization impact on landscape patterns in Beijing City, China: A spatial heterogeneity perspective. Ecol. Indic. 2017, 82, 50-60. [CrossRef]

33. Jiang, P.H.; Cheng, Q.W.; Zhang, Z.Z.; Tang, H.Q.; Li, M.C. The dynamic mechanism of landscape structure change of arable landscape system in China. Agric. Ecol. Environ. 2018, 251, 26-36. [CrossRef]

34. Peng, J.; Liu, Y.; Shen, H.; Xie, P.; Hu, X.; Wang, Y. Using impervious surfaces to detect urban expansion in Beijing of China in 2000. Chin. Geogr. Sci. 2016, 26, 229-243.

35. Su, S.L.; Ma, X.Y.; Xiao, R. Agricultural landscape pattern changes in response to urbanization atecoregional scale. Ecol. Indic. 2014, 40, 10-18. [CrossRef]

36. Li, S.F.; Marinova, D.; Zhao, D. Effects of population and land urbanization on China's environmental impact: Empirical analysis based on the extended STIRPAT model. Sustainability 2017, 9, 825.

37. Imhoff, M.L.; Lawrence, W.T.; Stutzer, D.C.; Elvidge, C.D. Assessing the Impact of Urban Sprawl on Soil Resources in the United States Using Nighttime "City Lights" Satellite Images and Digital Soils Maps. 2003. Available online: https:/ /landcover.usgs.gov /luhna/chap3.php (accessed on 24 May 2018).

38. Wen, Q.K.; Zhang, Z.X.; Shi, L.F. Extraction of basic trends of urban expansion in China over past 40 years from satellite images. Chin. Geogr. Sci. 2016, 26, 129-142. [CrossRef]

39. Lo Papa, G.; Palermo, V.; Dazzi, C. Is land-use change a cause of loss of pedodiversity? The case of the Mazzarone study area, Sicily. Geomorphology 2011, 135, 332-342. [CrossRef]

40. Dietzel, C.; Herold, M.; Hemphill, J.J.; Clarke, K.C. Spatio-temporal dynamics in California's Central Valley: Empirical links to urban theory. Int. J. Geogr. Inf. Sci. 2005, 19, 175-195. [CrossRef]

41. Amndson, R.; Guo, Y.; Gong, P. Soil diversity and land use in the United States. Ecosystems 2003, 6, 470-482. [CrossRef]

(C) 2018 by the authors. Licensee MDPI, Basel, Switzerland. This article is an open access article distributed under the terms and conditions of the Creative Commons Attribution (CC BY) license (http://creativecommons.org/licenses/by/4.0/). 